\title{
Antibacterial Activity of Selected Fractions Extract of Coptis chinensis Franch Rhizomes
}

\author{
Reyadh R Al-Rashidi ${ }^{1}$, Hisham Al-Shaikhli ${ }^{2}$, Rusul A Alsaray ${ }^{1}$, Tahrani Munusamy ${ }^{3}$, Radhi K. Obaid ${ }^{4}$ \\ 1 Assist. Lecturer/ Department of Dentistry, Alkut University College, 52001, Wasit, Iraq, ${ }^{2}$ Lecturer/ School of \\ Public health and Interdisciplinary Studies, Faculty of health and environmental sciences, Auckland University \\ of Technology, 1142, Auckland, New Zealand, 3 Researcher/School of Pharmacy, Management and Science \\ University, 40100, Shah Alam, Selangor Darul Ehsan, Malaysia, 4 Prof/ Department of Pharmacy, Alkut University \\ College, 52001, Wasit, Iraq
}

\begin{abstract}
The antibacterial activity of different fractions of selected extract of Coptis chinensis Franch rhizome was evaluated on gram positive bacteria. Three extracts were tested at concentrations ranging from $1 \mathrm{mg} /$ $\mathrm{ml}, 10 \mathrm{mg} / \mathrm{ml}$, and $100 \mathrm{mg} / \mathrm{ml}$ in vitro on three bacterial strains, Staphylococcus aureus, Streptococcus pneumoniae, and Bacillus anthracis, which was done by performing disc diffusion for growth inhibition. The methanol extract at concentrations of $100 \mathrm{mg} / \mathrm{ml}$ displayed the most significant zone of inhibition of (22.67 $\pm 3.055 \mathrm{~mm}),(21.67 \pm 3.512 \mathrm{~mm}),(16.67 \pm 1.528 \mathrm{~mm})$ against Streptococcus pneumoniae, Staphylococcus aureus, and Bacillus anthracis, respectively. The TLC separation of the extracts showed that each of them may contains constituents that are phenolic in nature. From the $\mathrm{R}_{\mathrm{f}}$ values of the spots found in the various extracts is that the Coptis chinensis Franch rhizome contains some other non-phenolic compounds responsible for its effect. The selected methanol extract is then subjected to column chromatography and collected 4 fractions. Out of the four fractions, F2 fraction demonstrates the most significant zone of inhibition of $15.00 \pm 1.000$ $\mathrm{mm}, 12.33 \pm 1.528 \mathrm{~mm}$ and $10.00 \pm 2.000 \mathrm{~mm}$ against Streptococcus pneumoniae, Staphylococcus aureus, and Bacillus anthracis, respectively.
\end{abstract}

Keywords: Coptis chinensis, Fractions, Antibacterial activity, Zone of inhibition

\section{Introduction}

Infectious diseases have persisted as a major health problem for almost half a century now, and there has been increasing incidence of resistance to currently available antibacterial ${ }^{1}$. There is the need for intensive studies for the possible discovery of new agents with antibacterial potentials ${ }^{1}$. Plants have provided a good source of antimicrobial activity. The primary benefits of using plant-derived medicines are that they are relatively safer than synthetic alternatives, offering profound therapeutic benefits, absence or very few side effects and

\section{Corresponding author:}

Reyadh R Al-Rashidi

Email: reyadh.radhi@alkutcollege.edu.iq reyadhalrashidi@gmail.com more affordable treatment ${ }^{2}$.

Wide range of medicinal plant parts is used for extract as raw drugs and they possess various medicinal properties. Usually, these plants are rich in a wide variety of secondary metabolites, such as tannins, terpenoids, alkaloids, and flavonoids, which have been found to have antimicrobial properties in vitro ${ }^{3}$. An example of traditional Chinese plant that possesses various medicinal properties is Coptis chinensis a member of Ranunculaceae family, is widely cultivated and produced in Sichuan, Yunnan, and Hubei. This herb is particularly endemic to the middle and southern regions of China. It comprises three main species, among these species, Coptis chinensis Franch is regarded as most widely used with a slight odor, very bitter taste, and contains the highest bioactive alkaloids content ${ }^{4}$. Extract of Coptis chinensis Franch has a strong antibacterial activity and is used for 
treating dysentery, diabetes, cholera, leukemia, and lung cancer. They are usually characterized by the presence of the major alkaloids: berberine, palmatine, coptisine, berberastine, and jatrorrhizine ${ }^{5}$. Additionally, aqueous extract of Coptis chinensis Franch containing bioactive alkaloids that have been applied widely in clinics, and recent studies discovered that aqueous Coptis chinensis Franch extracts expressed a hepatoprotective effect on carbon tetrachloride-induced acute liver hepatotoxicity in rats ${ }^{6}$, and also possessed analgesic effects in a rat model of irritable bowel syndrome ${ }^{7}$.

The purpose of this study was to evaluate the antibacterial activity of selected fractions extract prepared from the dried rhizomes of Coptis chinensis Franch on gram-positive bacteria, Staphylococcus aureus, Streptococcus pneumoniae, and Bacillus anthracis.

\section{Materials and Methods}

\section{Microbial strains}

Three strains of standard bacteria, Staphylococcus aureus, Streptococcus pneumonia, and Bacillus anthracis, were collected from the Microbiology Laboratory at Management and Science University in Selangor, Malaysia. All the three bacteria were supplied as cultures on Mueller-Hinton Agar (Mast Group Ltd.) plates. Plates were stored in the cold room $\left(2-4^{\circ} \mathrm{C}\right)$ until the study was started ${ }^{8}$.

\section{Plant material}

The rhizome of Coptis chinensis Franch has been collected locally from Chinese medicinal botany shop within the area of Klang, Selangor, Malaysia.

A total of 100 grams of Coptis chinensis Franch rhizomes were thoroughly cleaned and washed 2-3 times with running tap water and once with sterile distilled water in the lab to avoid dusts and other unwanted materials. These samples were then allowed to dry in the oven for 2 days at $45^{\circ} \mathrm{C}$. After drying, the rhizome part of the plant was grounded into fine powders using electrical blender. The grounded powders were then transferred into an airtight container and was utilized for extraction. This is to ensure the extraction to be more effective as smaller particles tend to have large surface area which help them to get in contact with the solvent, thus, ease the extraction of active compound ${ }^{8}$.

\section{Extraction of plant material}

The dried Coptis chinensis Franch rhizomes are then extracted using Soxhlet extractor. This extraction is performed at room temperature $\left(20^{\circ} \mathrm{C}-25^{\circ} \mathrm{C}\right)$ by using $80 \%$ methanol, $70 \%$ ethanol and chloroform as solvent in the ratio of solvent:sample $=10: 1 \mathrm{v} / \mathrm{w} .20$ grams of dried, grounded powder was extracted in $200 \mathrm{ml}$ of the above mentioned solvent via soxhlet extraction method. The solvents were obtained from the Research Laboratory of Management and Science University in Selangor, Malaysia. The whole extraction process took place for nearly 8 hours. Once the extraction was completed, the obtained extract was first filtered using Whatsman filter papers and the solvent was removed by rotary evaporator under reduced pressure at temperatures below $45^{\circ} \mathrm{C}$ in order to obtain a concentrated extract. The remaining thick semisolid extract was scrapped out from the evaporator flask using a spatula. Each different concentrated extract was then transferred into a container and kept in cold room until further use ${ }^{8}$.

\section{Preliminary antibacterial test}

Before testing with bacteria, medium for bacterial growth were prepared. The medium was prepared by dissolving $15.2 \mathrm{~g}$ of Mueller Hinton Agar in $400 \mathrm{ml}$ of distilled water in a schott bottle. These dissolved medium were autoclaved at $15 \mathrm{lbs}$. pressure $\left(121^{\circ} \mathrm{C}\right)$ for 15 minutes. The sterilized media was mixed well and poured into sterile dish plates, with $15 \mathrm{ml}$ per plate while still molten. The plates were set aside for storage or further use.

Pattern of inoculation lines for each bacterium, Staphylococcus aureus, Streptococcus pneumoniae and Bacillus anthracis were made on the agar. .Then, the impregnated discs containing anti-microbial agent, vancomycin (positive control), the resulting crude extract of different concentration (i.e. $1 \mathrm{mg} / \mathrm{ml}, 10 \mathrm{mg} / \mathrm{ml}, 100$ $\mathrm{mg} / \mathrm{ml})$, and solvent (80\% methanol, $70 \%$ ethanol and chloroform) as negative control were arranged on the surface of the inoculated plates and incubated at $37^{\circ} \mathrm{C} \pm$ 0.05 for 24 hours. This method is known as preliminary antibacterial evaluation. Extract yielding greater zone of inhibition was used further for fractionation ${ }^{9}$. 


\section{Thin layer chromatography}

Thin layer chromatography (TLC) is carried out to isolate the principle components that were present in most effective extracts of plant. In this experiment, ratios of different solvent systems of different polarities are prepared. Selection of solvent is normally done on the basis of increasing polarity ${ }^{10}$.

Nine different solvent systems were prepared by adding ethyl acetate and hexane in different ratios. Each of these solvent was prepared for $10 \mathrm{ml}$ and poured into different beakers for 9 beakers. Each beaker was placed with a TLC plate in it, which has been spotted with the selected extract concentration (methanolic crude extract - $100 \mathrm{mg} / \mathrm{ml}$ ) from preliminary antibacterial test on it via capillary tube. The beakers were then covered with aluminum foil and left for few minutes for the solvent to rise up to the top of the TLC plate. Detection of spots was by spraying plates with ferric chloride, iodine and $\mathrm{DPPH}$, and viewing under UV lamp ${ }^{11}$. The $\mathrm{R}_{\mathrm{f}}$ value of spot formed on each TLC plate was then recorded. The solvent with the best $R_{f}$ value was then selected to be used for column chromatography

\section{Fractionation of crude extract}

The selected extract, methanol crude extract, $100 \mathrm{mg} /$ $\mathrm{ml}$, was fractioned by filter column chromatography over $300 \mathrm{~g}$ of silica gel 60 (S). The column chromatography was eluted with approximately $3.0 \mathrm{~L}$ of the solvent hexane, in order of increasing polarity, until a clear extract was obtained at the end of the elution ${ }^{9}$. As soon as the colored compound begins to elute, 4 different fractions of $20 \mathrm{~mL}$ were collected at different times. Fractions were stored at $4^{\circ} \mathrm{C}$.

Antibacterial test using the agar diffusion method (disc) and diameter of the inhibition zone

The in vitro antibacterial activity of the methanol crude extract fractions from Coptis chinensis Franch rhizomes are determined by the disc diffusion method. The complete diffusion of samples into the MuellerHinton Agar was visually confirmed. Mueller-Hinton Agar medium is sterilized and poured into the plate; the medium is allowed to settle and stored at $4{ }^{\circ} \mathrm{C}$. The three bacterial strains, Staphylococcus aureus, Streptococcus pneumonia, and Bacillus anthracis were cultured overnight at $37^{\circ} \mathrm{C}$ in Mueller-Hinton Agar. The bacterial colonies were transferred into a sterile loop or cotton swab and mixed well from the fresh agar plate. The suspension was adjusted to achieve a turbidity equivalent to a 0.5 McFarland turbidity standard. This suspension resulted in a suspension containing approximately $1 \times 10^{9} \mathrm{CFU} / \mathrm{mL}{ }^{[7]} .1 \mathrm{~mL}$ of inoculum of the bacterial strains $\left(10^{6} \mathrm{CFU} / \mathrm{mL}\right)$ was poured into petri dishes $(90 \mathrm{~mm})$ already filled with Mueller-Hinton Agar. Then, $3 \mathrm{~mm}$ wells were used and filled with $20 \mu \mathrm{L}$ of samples. First one was placed with a positive reference Vancomycin (30 $\mu \mathrm{g} / \mathrm{disc}$ ) (Oxoid), the second was with a negative control, $80 \%$ methanol disc, and the third was with one fraction of methanol crude extract. Three hrs. were required for pre-incubated the Petri dishes at room temperature, allowing the complete diffusion of the samples; then, they were incubated at $37^{\circ} \mathrm{C}$ for $24 \mathrm{hrs}$

${ }^{3}$. Three replicates of plates were then examined for the presence of inhibitory zone and the diameter of the zone $(\mathrm{mm})$ formed around the disc was measured.

\section{Statistical Analysis}

Experiments were conducted in triplicates, and the values presented as their mean \pm standard deviation. Analysis was done with ANOVA with the significance level at $\mathrm{p}<0.05$.

\section{Results and Discussion}

The rhizomes of Coptis chinensis Franch were extracted with three different solvent systems, $80 \%$ methanol, $70 \%$ ethanol and chloroform as a preliminary antibacterial evaluation. Extracts were evaluated at concentrations ranging from $1 \mathrm{mg} /$ $\mathrm{ml}, 10 \mathrm{mg} / \mathrm{ml}$, and $100 \mathrm{mg} / \mathrm{ml}$ in vitro against three bacterial strains, Staphylococcus aureus, Streptococcus pneumoniae, and Bacillus anthracis. Zone of inhibition of these different extracts were compared with that of standards antibiotic, Vancomycin, for antibacterial activity. The majority of these different extracts had inhibitory effect at different concentrations (Table 1). Results indicated that methanol extract at concentrations of $100 \mathrm{mg} / \mathrm{ml}$ displayed the most significant zone of inhibition of $22.67 \pm 3.055 \mathrm{~mm}, 21.67 \pm 3.512 \mathrm{~mm}$ and $16.67 \pm 1.528 \mathrm{~mm}$ against Streptococcus pneumoniae, Staphylococc 
Table 1. Zone of Inhibition of Different Extracts Concentration on Staphylococcus aureus, Streptococcus pneumonia and Bacillus anthracis. ${ }^{\text {a }}$

\begin{tabular}{|c|c|c|c|c|}
\hline \multirow{2}{*}{ Bacterial strains } & \multirow{2}{*}{$\begin{array}{l}\text { Extract conc. } \\
(\mathrm{mg} / \mathrm{ml})\end{array}$} & \multicolumn{3}{|c|}{ Diameter of inhibition zone $(\mathrm{mm}) \mathrm{b}$} \\
\hline & & $80 \%$ methanol & $70 \%$ Ethanol & Chloroform \\
\hline $\begin{array}{l}\text { Staphylococcus } \\
\text { aureus }\end{array}$ & $\begin{array}{l}1 \\
10 \\
100\end{array}$ & $\begin{array}{l}0.00 \pm 0.000 \\
13.0 \pm 03.606 \\
21.67 \pm 3.512\end{array}$ & $\begin{array}{l}0.00 \pm 0.000 \\
0.00 \pm 0.000 \\
11.33 \pm 9.815\end{array}$ & $\begin{array}{l}0.00 \pm 0.000 \\
3.67 \pm 4.933 \\
16.33 \pm 2.517\end{array}$ \\
\hline $\begin{array}{l}\text { Streptococcus } \\
\text { pneumonia }\end{array}$ & $\begin{array}{l}1 \\
10 \\
100\end{array}$ & $\begin{array}{l}0.00 \pm 0.000 \\
6.67 \pm 5.774 \\
22.67 \pm 3.055\end{array}$ & $\begin{array}{l}2.00 \pm 3.646 \\
10.00 \pm 1.000 \\
17.33 \pm 2.517\end{array}$ & $\begin{array}{l}0.00 \pm 0.000 \\
8.33 \pm 1.155 \\
17.33 \pm 2.517\end{array}$ \\
\hline $\begin{array}{l}\text { Bacillus } \\
\text { anthracis }\end{array}$ & $\begin{array}{l}1 \\
10 \\
100\end{array}$ & $\begin{array}{l}2.00 \pm 3.404 \\
12.00 \pm 2.646 \\
16.76 \pm 1.528\end{array}$ & $\begin{array}{l}0.00 \pm 0.000 \\
6.33 \pm 0.577 \\
16.00 \pm 1.000\end{array}$ & $\begin{array}{l}5.67 \pm 0.577 \\
6.67 \pm 0.577 \\
17.33 \pm 2.887\end{array}$ \\
\hline
\end{tabular}

${ }^{a}$ Values are mean \pm SD of three replicates, ${ }^{b}$ diameter of inhibition zone $(\mathrm{mm})$ include the disc diameter.

us aureus, and Bacillus anthracis, respectively. In comparison with standard antibiotic, Vancomycin (30 $\mu \mathrm{g} /$ disc), results showed that there was no significant differences $(p>0.05)$ in the diameter of zone of inhibition. This results indicated that the Coptis chinensis Franch rhizome of methanol extract inherits a potential antibacterial property compared to ethanol and chloroform extract.

The thin layer chromatography (TLC) separation of the extracts show that each of them may contains constituents that are phenolic in nature (Tables 2). From the $\mathrm{R}_{\mathrm{f}}$ values of the spots found in the various extracts is that the plant contains some other non-phenolic compounds responsible for its effect ${ }^{11}$. Phenolic compounds are also reported to have antioxidant effect ${ }^{12}$. Some non-phenolic compounds have been reported to show antioxidant activity and antimicrobial effect. Therefore it can be inferred that it is the presence of these types of constituents that are responsible for the observed antibacterial activity of this plant. Based on $\mathrm{R}_{\mathrm{f}}$ values and number of spots formed, the solvent ratio of 9:1 shows a better result and was used for fractionation via column chromatography.

Table 2. Retention Factor $\left(\mathbf{R}_{\mathrm{f}}\right)$ Values Formed by Different Solvents Ratios

\begin{tabular}{|l|l|l|l|l|}
\hline Solvent Ratios & \multicolumn{2}{l|}{ Rf Value } & \multirow{2}{*}{ Color Formed } \\
\hline $\begin{array}{l}\text { Hexane: Ethyl } \\
\text { acetate }\end{array}$ & $\mathbf{1}$ stSpot & 2ndSpot & 3edSpot \\
\hline $1: 9$ & - & - & - & - \\
\hline $2: 8$ & - & - & - & - \\
\hline $3: 7$ & - & - & - & - \\
\hline $4: 6$ & 0.88 & - & - & Yellow \\
\hline $5: 5$ & 0.30 & - & - & Yellow \\
\hline $6: 4$ & 0.20 & 0.98 & - & Brown \\
\hline $7: 3$ & 0.33 & 0.64 & - & Brown \\
\hline $8: 2$ & 0.50 & 0.68 & - & Brown \\
\hline $9: 1$ & 0.38 & 0.58 & 0.84 & Brown \\
\hline
\end{tabular}


Four fractions, $20 \mathrm{ml}$ each, of Coptis chinensis Franch methanol extract were collected. Fractions obtained were in different colors (Table 3), this indicates the existence of various components in the extract. The antibacterial activity of each fractions was determined. To perform a rapid screening study of potential antibacterial activity, a disc diffusion assay was used to evaluate the inhibitory effect. The majority of these different fractions had inhibitory effect against
Staphylococcus aureus, Streptococcus pneumoniae and Bacillus anthracis after incubated for 24 hours. Among all of these fractions, second fraction (F2) demonstrates the greatest inhibition zones as compared to other fractions. Based on the comparison table, F2 displayed inhibition zones of $15.00 \pm 1.000 \mathrm{~mm}$ against Streptococcus pneumoniae, followed by $12.33 \pm 1.528$ $\mathrm{mm}$ against Staphylococcus aureus, and $10.00 \pm 2.000$ $\mathrm{mm}$ against Bacillus anthracis.

Table 3. Fractions of Methanol Extract of Coptic chinensis Franch Rhizome Formed by Column Chromatography.

\begin{tabular}{|l|l|l|l|}
\hline Methanol Fractions & Volume Collected (ml) & Color Formed & $\begin{array}{l}\text { Retention Time (RT) of } \\
\text { collection (min.) }\end{array}$ \\
\hline F1 & 20 & Yellow & 30 \\
\hline F2 & 20 & Yellow - Orange & 40 \\
\hline F3 & 20 & Orange & 55 \\
\hline F4 & 20 & Dark Orange & 75 \\
\hline
\end{tabular}

Based on one-way ANOVA analysis, F2 and F3 are having significantly higher $(p<0.001)$ antibacterial activity than F1 and F4. Within both of these fractions, F2 \& F3 are not statistically different ( $p>0.05)$, which means that both have almost similar inhibition effect.

Standard antibiotics, Vancomycin (30 $\mathrm{g} / \mathrm{disc})$ showed much higher significant difference $(p<$ 0.001) than other fractions on Staphylococcus aureus, Streptococcus pneumoniae and Bacillus anthracis. This explains that treatment with glycopeptide antibiotics, Vancomycin is more effective and possesses more antibacterial activity compared to these four fractions of Coptis chinensis Franch of methanol extracts on gram positive bacteria. Therefore, this clearly proves that the fractions of Coptis chinensis Franch rhizome of methanolic extract, particularly F2, inherits a potential antibacterial property against Staphylococcus aureus, Streptococcus pneumoniae and Bacillus anthracis.

\section{Conclusion}

The finding of the study revealed that all the fractions obtained from Coptis chinensis Franch rhizomes of methanol extract did possess antibacterial activity against Staphylococcus aureus, Streptococcus pneumoniae and Bacillus anthracis. Among these fractions, F2 fraction showed more inhibition against those bacterial strains. Future studies are suggested for identification of the minimum inhibitory concentration (MIC) and phytochemical testing of Coptis chinensis Franch rhizome of methanol extract fractions.

Ethical Clearance: The Research Ethical Committee at scientific research by ethical approval of both $\mathrm{MOH}$ and MOHSER in Iraq

\section{Conflict of Interest: Non}

Funding: Self-funding

\section{References}

1. Okoye T, Akah P, Okoli C, et al. Antimicrobial and antispasmodic activity of leaf extract and fractions of Stachytarpheta cayennensis. Asian Pacific Journal of tropical medicine 2010; 3: 189-192.

2. Iwu MW, Duncan AR and Okunji CO. New antimicrobials of plant origin. Perspectives on new 
crops and new uses ASHS Press, Alexandria, VA 1999: 457-462.

3. Tan BK and Vanitha J. Immunomodulatory and antimicrobial effects of some traditional Chinese medicinal herbs: a review. Current medicinal chemistry 2004; 11: 1423-1430.

4. Teng H and Choi YH. Optimization of extraction of total alkaloid content from rhizome coptidis (Coptis chinensis Franch) using response surface methodology. Journal of the Korean Society for Applied Biological Chemistry 2012; 55: 303-309.

5. Kim DG, Simborio HLT, Reyes AWB, et al. Antibacterial effects of Coptis chinensis Franch against Brucella abortus. Journal of Agriculture \& Life Science 2014; 48: 107-114.

6. YeX, Feng Y, Tong Y, et al. Hepatoprotective effects of Coptidis rhizoma aqueous extract on carbon tetrachloride-induced acute liver hepatotoxicity in rats. Journal of Ethnopharmacology 2009; 124: 130-136.

7. Tjong Y, Ip S, Lao L, et al. Analgesic effect of Coptis chinensis rhizomes (Coptidis Rhizoma) extract on rat model of irritable bowel syndrome. Journal of ethnopharmacology 2011; 135: 754761.
8. Liu B, Li W, Chang Y, et al. Extraction of berberine from rhizome of Coptis chinensis Franch using supercritical fluid extraction. Journal of Pharmaceutical and Biomedical Analysis 2006; 41: 1056-1060.

9. Martins S, Amorim EL, Sobrinho TJP, et al. Antibacterial activity of crude methanolic extract and fractions obtained from Larrea tridentata leaves. Industrial Crops and Products 2013; 41: 306-311.

10. Lee M-H, Kwon HA, Kwon D-Y, et al. Antibacterial activity of medicinal herb extracts against Salmonella. International Journal of food microbiology 2006; 111: 270-275.

11. Elechi $\mathrm{N}$ and Igboh $\mathrm{O}$. Antibacterial activities of the methanol extract and fractions of the leaf of Eriosema psoraleoides (Lam.) G. Don (leguminosae). International Journal of Pharmaceutical Sciences and Research 2017; 8: 698.

12. Koolen HH, da Silva FM, Gozzo FC, et al. Antioxidant, antimicrobial activities and characterization of phenolic compounds from buriti (Mauritia flexuosa L. f.) by UPLC-ESI-MS/MS. Food Research International 2013; 51: 467-473. 